\title{
Liver-Histological Improvement after Capsaicin Administration in Mice with Aflatoxin B1 Toxication
}

\author{
Mohammad Sukmanadii ${ }^{1}$, Mustofa Helmi Effendi ${ }^{2, *}$, Faisal Fikri ${ }^{3}$, Muhammad Thohawi Elziyad Purnama ${ }^{4}$
}

Mohammad Sukmanadi', Mustofa Helmi Effendi ${ }^{2, *}$, Faisal Fikri ${ }^{3}$, Muhammad Thohawi Elziyad Purnama ${ }^{4}$

'SubDivision of Veterinary Pharmacy, Division of Veterinary Basic Science, Faculty of Veterinary Medicine, Universitas Airlangga, Surabaya, INDONESIA

${ }^{2}$ Division of Veterinary Public Health, Department of Veterinary Science, Faculty of Veterinary Medicine, Universitas Airlangga, Surabaya, INDONESIA.

${ }^{3}$ SubDivision of Veterinary Pharmacology, Division of Veterinary Basic Science,

Faculty of Veterinary Medicine, Universitas Airlangga, Surabaya, INDONESIA.

${ }^{4}$ Division of Veterinary Anatomy, Department of Veterinary Science, Faculty of Veterinary Medicine, Universitas Airlangga, Surabaya INDONESIA.

\section{Correspondence}

\section{Mustofa Helmi Effendi}

Division of Veterinary Public Health, Department of Veterinary Science, Faculty of Veterinary Medicine, Universitas Airlangga, Surabaya, INDONESIA. E-mail: mheffendi@yahoo.com

\section{History}

- Submission Date: 06-09-2021

- Review completed: 18-09-2021.

- Accepted Date: 08-10-2021.

DOI : 10.5530/pj.2021.13.202

Article Available online

http://www.phcogj.com/v13/i6

Copyright

(C) 2021 Phcogj.Com. This is an open access article distributed under the terms of the Creative Commons Attribution 4.0 International license.

\section{ABSTRACT}

Context: Public health issues are considered to provide safety for public consumption. The distribution of mycotoxins in food is still a concern to be solved. Capsaicin is a property in chili that inhibits the biotransformation of mycotoxins by modifying the activity of liver enzymes in phase I. Objectives: A total of 20 mice were divided into 4 treatment groups, namely (T0) $0.5 \mathrm{ml}$ of polyethylene glycol, (T1) $0.5 \mathrm{ml}$ of capsaicin $+0.5 \mathrm{ml}$ of polyethylene glycol, (T2) $0.1 \mathrm{ml}$ of aflatoxin B1 $+0.5 \mathrm{ml}$ of polyethylene glycol, (T3) $0.1 \mathrm{ml}$ of aflatoxin B1 $+0.5 \mathrm{ml}$ of capsaicin, respectively. Methods: Liver histology was performed with hematoxylin-eosin staining and then evaluated descriptively. Result: The T3 group showed significant improvement in sublobular vein, interlobular vein, centralis vein, interlobular duct. Meanwhile, based on scores of hepatocyte form, focal necrosis, hypertrophy, fibrosis, cholestasis, and steatosis were evaluated for improvement in the T3 group. Conclusion: Capsaicin was revealed to improve the liver histology in mice with aflatoxin B1 toxication.

Key words: Aflatoxin B1, Capsaicin, Liver, Public health

\section{INTRODUCTION}

A mycotoxin generally has more than one type of target organ, for example the target organs of aflatoxin B1 (AFB1) are the liver, kidneys, heart, and nervous system. Mycotoxins that are hepatotoxic can cause damage to hepatocyte structures and impaired liver function. Damage to the hepatocyte structure can occur in hepatocytes found in the liver lobules. ${ }^{1}$

Exposure to AFB1 into the body results in a toxic response. The intensity of the toxic response is influenced by the dose of exposure, route of entry, length of time consuming, gender and type of organism consuming. The higher the dose of exposure to a toxic substance, the higher the resulting toxic response. ${ }^{2}$ The concept of doseresponse relationship also suggests that there is a relationship between the dose of exposure to a toxicant and the resulting toxic response. The effects of aflatoxicosis in animals can be acute, subacute and chronic. Both acute and chronic effects mainly occur in the liver, because the main target organ for the toxicity effect is the liver ${ }^{3}$.

Capsaicin can reduce PI3K expression, indicating that capsaicin blocks the PI3K/Akt/mTOR pathway. However, p38 phosphorylation was not affected to clarify the effects of capsaicin and cell proliferation on the PI3K/Akt/mTOR, wortmannin (PI3K inhibitor) and rapamycin (mTOR) pathways ${ }^{4}$. By examining the phosphorylation of proteins in this pathway. The data suggest that phosphorylation of Akt, ERK, p-GSK3- $\beta$, and mTOR can be inhibited by capsaicin through mediation by the PI3K/ Akt/mTOR pathway playing important roles in regulating cell cycle, apoptosis, and autophagy ${ }^{5}$.

Capsaicin's ability to inhibit the proliferation of various cell lines, through apoptosis is associated with the generation of reactive oxygen species
(ROS), activation of the JNK pathway, decreased mitochondrial depolarization and release of cytochrome-c, thus leading to activation of the caspase-3 cascade. Capsaicin-mediated ROS generation leads to activation of the mitogendependent apoptotic signaling kinase-activated protein kinase (MAPK3) pathway ${ }^{6}$. Capsaicin modulates the phosphorylation of the MAPK cascade signaling protein. Effects of capsaicin on the MAPK signaling pathway, which is critical for cell survival and growth. Capsaicin decreases the expression of phosphorylated ERK 1. A two-molecule complex consisting of a ligand with a target protein ligand can be a chemical compound or a small molecule of AFB1 while the target can be a macromolecule or a major protein ${ }^{7}$. In this study, the efficacy of capsaicin in mice liver with AFB1 toxication were evaluated for the following variables: vascular diameter, hepatocyte form, focal necrosis, hypertrophy, fibrosis, cholestasis, and steatosis.

\section{MATERIAL AND METHODS}

\section{Ethical approval}

This research was approved by the Laboratory Animal Ethics Committee, Faculty of Veterinary Medicine, Airlangga University with certificate No. . KE. 198. 12. 2019. This approval prevents animal abuse and animal stress during treatment.

\section{Experimental design}

A total of 100 gram chili were extracted using rotary evaporator then incubated prior the treatment. The capsaicin was purified using highly performance liquid chromatography ${ }^{8}$. Acclimatization in mice was carried out for a week. A total of 20 mice were used as sample, divided into four group i.e. (T0) administered $0,5 \mathrm{ml}$ of polyethylene glycol, (T1) administered 0,5 $\mathrm{ml}$ of capsaicin $+0,5 \mathrm{ml}$ of polyethylene glycol, (T2) administered $0,1 \mathrm{ml}$ of AFB1 $+0,5 \mathrm{ml}$ of polyethylene 
glycol, (T3) administered $0,1 \mathrm{ml}$ of AFB1 $+0,5 \mathrm{ml}$ of capsaicin, respectively. All treatments were carried out for one month and then the mice were euthanized with cervical dislocation. Liver organs were preserved and fixed for hematoxylin eosin staining.

\section{Histological observations in the liver}

Briefly, the liver was immersed in $10 \%$ neutral buffer formalin solution and then dissected. Then the dehydration process was carried out in graded alcohol concentrations, i.e. 70\%, 80\%, 90\% alcohol, each for 2 hours. Then it was cleared with xylol then printed using paraffin so that the preparations were printed in paraffin blocks and stored in the refrigerator. The paraffin blocks were then cut into thin strips of 5-6 m using a microtome. The pieces were floated in warm water at $60 \mathrm{oC}$ for 24 hours. The preparation was then removed and placed in an object glass for hematoxylin eosin staining. Measurement of the diameter of sublobular vein, interlobular vein, centralis vein, and interlobular duct were examined under a trinocular microscope ${ }^{9}$.

\section{Data analysis}

Data are represented as mean \pm standard deviation. All variables were analyzed using ANOVA followed by a post hoc Tukey multiple comparison test $(\mathrm{p}<0.05)$.

\section{RESULTS}

Based on observations of vascular vessels and portal triad areas showed significant improvement $(\mathrm{p}<0.05)$ in the $\mathrm{T} 3$ group. The diameters of the sublobular vein, interlobular vein, centralis vein, and interlobular duct were observed to be smaller than the T2 group, respectively (Table 1). In addition, the histological findings of hepatocyte form, focal necrosis, hypertrophy, fibrosis, cholestasis, and steatosis were improved in the T3 group (Table 2). This finding also suggests a positive correlation on the regeneration of hepatocyte cells.

\section{DISCUSSION}

Capsaicin can modulate the level of expression of genes and enzymes involved in cell proliferation, cell cycle, signal transduction, apoptosis, therefore exhibiting hepatoprotective activity. The mechanism of capsaicin exerts anti-proliferative effects, cell cycle arrest, autophagy and apoptosis, inhibits cell growth and increases G1 cell cycle arrest. Capsaicin-induced autophagy via involvement of the PI3K/Beclin-1/
Bcl-2 signaling pathway ${ }^{10}$. Capsaicin induces autophagy by enhancing caspase-3 activity to induce apoptosis, indicating a correlation of blocking the PI3K/Akt/mTOR pathway. Capsaicin administration can decrease the expression level of phosphorylated ERK 1, p38 MAPK ${ }^{11}$.

Capsaicin can modulate the phosphorylation of the MAPK cascade signaling protein. Effects of capsaicin on the MAPK signaling pathway, which is critical for cell survival and growth during development and carcinogenesis. Capsaicin treatment decreased the expression of phosphorylated ERK 1, slightly decreased the phosphorylation of p38 and JNK. Total levels of ERK 1, JNK and p38 MAPK did not change after treatment with capsaicin ${ }^{12}$.

These alkaloid compounds have been found to inhibit cancer growth and development in vitro and in vivo and to induce apoptosis in various types of cancer cells. (3-8). The molecular mechanisms underlying capsaicin-induced apoptosis are cell type dependent ${ }^{13}$. Despite the cumulative evidence for the tumor suppressive effect of capsaicin, few studies have definitively carried out the effects of capsaicin on cell signaling and the molecular pathways leading to apoptosis in gastric cancer ${ }^{14}$.

Hepatic injury can be categorized by a number of systems, some systems based on the resulting histologic lesion (inflammation, necrosis, cholestasis), others the type of injury (cytotoxic, cholestatic, mixed), but the emergence of newer insights that provide insight into injury at the molecular level has gave rise to a more focused schema for understanding and categorizing hepatic injury ${ }^{15}$. In an overdose, highenergy reactive metabolites can form covalent bonds with proteins or nucleic acids. Under conditions of acute toxicity, metabolites bind to essential cellular enzymes that can cause injury or even cell death ${ }^{16}$

The results of histopathological examination showed that the oral administration of AFB1 in mice caused damage to the hepatocyte structure. Damage to the hepatocyte structure is characterized by degenerative changes and necrosis. Hepatic injury variables assessed in this study were degeneration, congestion, and necrosis which are markers of sensitive liver cell damage because they are located in the cytoplasm and only appear after liver cell damage occurs. The average liver histopathic changes before and after treatment are listed in Table 2.

Degeneration is damage to the hepatocyte structure which is characterized by the following characteristics: swollen hepatocytes, granular cytoplasm, and inhomogeneous appearance. This is due to the

Table 1: The vascular vessel evaluation in the liver during treatment.

\begin{tabular}{|c|c|c|c|c|}
\hline Group & Sublobular vein & Interlobular vein & Centralis vein & Interlobular duct \\
\hline T0 & $2,2 \pm 0,84^{\mathrm{a},+* *}$ & $1,8 \pm 0,45^{\mathrm{a}^{, * * *}}$ & $1,6 \pm 0,55^{\mathrm{a}, * *}$ & $1,0 \pm 1,00^{\mathrm{a}, * *+}$ \\
\hline $\mathrm{T} 1$ & $6,6 \pm 0,89^{\mathrm{b}, * * *}$ & $5,8 \pm 0,45^{\mathrm{b}, * * *}$ & $6,6 \pm 0,55^{b^{, * * *}}$ & $3,4 \pm 0,55^{\mathrm{b}, * * *}$ \\
\hline $\mathrm{T} 2$ & $11,2 \pm 1,30^{c}$ & $11,2 \pm 1,64^{\mathrm{d}}$ & $11,0 \pm 1,22^{\mathrm{c}}$ & $9,8 \pm 0,84^{\mathrm{d}}$ \\
\hline T3 & $8,2 \pm 1,48^{\mathrm{b}, *}$ & $8,4 \pm 0,89^{c^{* * *}}$ & $7,4 \pm 1,14^{\mathrm{b}, * * *}$ & $6,8 \pm 0,84^{c^{x+x}}$ \\
\hline
\end{tabular}

Values are expressed in mean \pm standard deviation ( $n=5$ animals for each four groups). One-way analysis of variance was carried out followed by post hoc Tukey multiple comparisons test. Values are represented statistically when ${ }^{\mathrm{a}, \mathrm{b}, \mathrm{c}}$ in comparison with the T0 group; * $<0.05,{ }^{* *}<0.01$, and ${ }^{* * *}<0.001$, in comparison with the T2 group.

Table 2: The histological finding in the liver during treatment.

\begin{tabular}{|c|c|c|c|c|}
\hline Variables & TO & T1 & T2 & T3 \\
\hline Hepatocyte form & $0,4 \pm 0,55^{a^{a * * *}}$ & $1,0 \pm 0,71^{\mathrm{a}^{, * * *}}$ & $3,4 \pm 0,55^{b}$ & $2,4 \pm 0,55^{b}$ \\
\hline Focal necrosis & $0,0 \pm 0,00^{a^{a, * x}}$ & $0,6 \pm 0,55^{a^{,+* *}}$ & $3,6 \pm 0,55^{c}$ & $2,2 \pm 0,45^{\mathrm{b}, * *}$ \\
\hline Hypertrophy & $0,2 \pm 0,45^{a^{a * * x}}$ & $1,0 \pm 0,71^{a^{, * * *}}$ & $3,4 \pm 0,55^{\mathrm{c}}$ & $2,0 \pm 0,00^{\mathrm{b}, * *}$ \\
\hline Fibrosis & $0,0 \pm 0,00^{a^{a, * * *}}$ & $1,0 \pm 0,71^{\mathrm{b}, * *}$ & $3,2 \pm 0,45^{c}$ & $1,8 \pm 0,45^{\mathrm{b}, * *}$ \\
\hline Cholestasis & $0,2 \pm 0,45^{a^{a+x+}}$ & $1,0 \pm 0,71^{a^{, * * *}}$ & $3,6 \pm 0,55^{c}$ & $2,0 \pm 0,00^{\mathrm{b}, \text {,**}}$ \\
\hline Steatosis & $0,2 \pm 0,45^{a^{a, * x}}$ & $0,8 \pm 0,84^{\mathrm{a}^{, * * *}}$ & $3,6 \pm 0,55^{c}$ & $2,0 \pm 0,71^{\mathrm{b}, x+}$ \\
\hline
\end{tabular}

Values are expressed in mean \pm standard deviation ( $n=5$ animals for each four groups). One-way analysis of variance was carried out followed by post hoc Tukey multiple comparisons test. Values are represented statistically when a,b, in comparison with the T0 group; * $<0.05,{ }^{* *}<0.01$, and ${ }^{* * *}<0.001$, in comparison with the T2 group. 


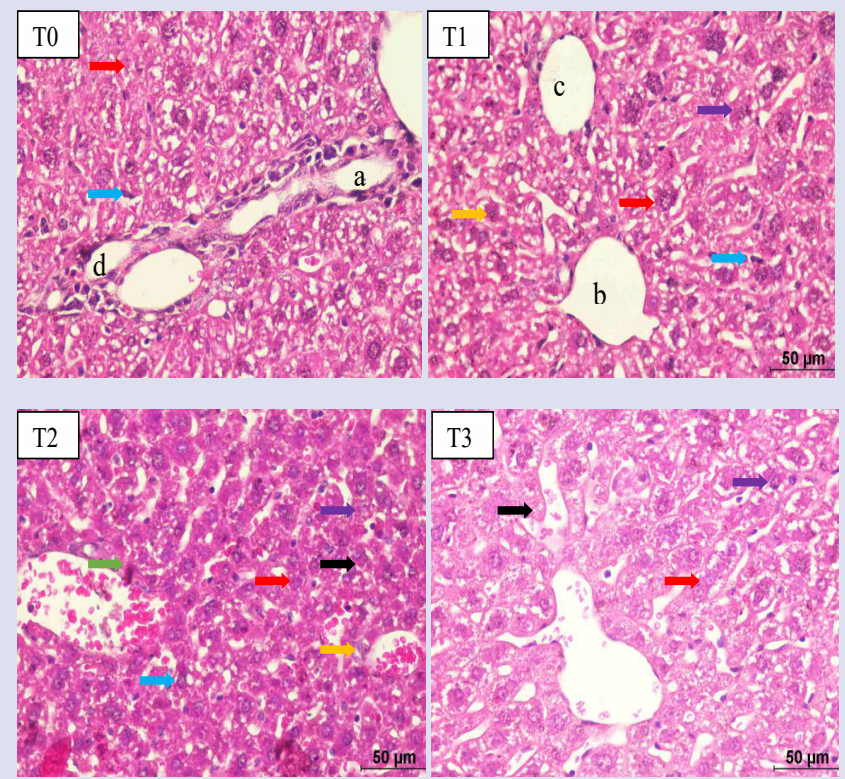

Figure 1. Histological findings in the liver. (a) Sublobular vein; (b) Interlobular vein; (c) Centralis vein; (d) Interlobular duct; $\rightarrow$ Hepatocyte form; $\rightarrow$ Focal necrosis; $\rightarrow$ Hypertrophy; $\rightarrow$ Fibrosis; $\rightarrow$ Cholestasis; $\rightarrow$ Steatosis

entry of fluid into the hepatocytes, so that the cells swell. Cell organelles also absorb fluid and swell, causing the cytoplasm to appear granular ${ }^{17}$. Degeneration is also characterized by the following characteristics: the cytoplasm undergoes vacuolization, the vacuoles appear clear and occurs due to an increase in fluid entry into the cell and then enters the vacuoles. characterized by the following characteristics: in the cytoplasm of the hepatocyte a large vacuole filled with fat is formed, so that the nucleus is pushed to the edge of the cell. In the administration of Capsaicin alone and control there is degeneration of hepatocytes, which is a normal program of hepatocytes, because cells that regenerate quickly, such as hepatocytes and muscle cells ${ }^{18}$.

Necrosis or cell death is a continuation of degeneration, it can also occur as a result of continued congestion. Congestion that gets worse results in a buildup of deoxyhemoglobin. Static blood that does not contain oxygen for a long time results in severe hypoxia which causes cell death ${ }^{19}$.

This hepatic impairment can be compensated for by plasma membrane sodium, which relies on the $\mathrm{Na}+\mathrm{K}+$-ATPase pump to remove sodium from the cell. Harmful agents can interfere with these membraneregulated processes by increasing plasma permeability to $\mathrm{Na}+$ thereby exceeding the pump's capacity to expel ions, damaging the pump directly, or interfering with ATP synthesis. The accumulation of sodium in the cell causes an increase in intracellular water to maintain an isosmotic condition and then the cell swells ${ }^{20}$.

Fat degeneration is the accumulation of fat or triglycerides in the cytoplasm of hepatocytes, fat in hepatocytes does not always indicate pathological changes, the etiology of fat degeneration can come from toxins, protein malnutrition, diabetes mellitus, obesity and anoxia ${ }^{21}$.

The inhibition of the activity of respiratory enzymes due to exposure to AFB1 results in inhibition of metabolism in hepatocyte cells resulting in a decrease in ATP which results in damage to the hepatocyte structure. Damage to mitochondria also results in inhibition of cellular respiration, because enzymes are released from the damaged mitochondria, resulting in hepatocyte death ${ }^{22}$.

Many inflammatory cells have a negative effect on liver function. Inflammatory cells can normally be found in the hepatic vein area because they are lymphoid follicles as a defense in the hepatic portal area in certain numbers, the presence of necrosis and apoptosis of hepatocytes, and the presence of inflammatory cells such as neutrophils, lymphocytes, and plasma cells which indicate the occurrence of acute hepatitis ${ }^{23}$.

Chili fruit is one of the plants that has a pharmacological effect, chili has a pungent taste derived from capsaicinoid compounds ${ }^{8}$. Capsaicin is the main compound capsaicinoid widely used in various therapies, including migraine, neuralgia, chronic pain, arthritis, and diabetic neuropathic, capsaicin also has antioxidant properties ${ }^{24}$.

\section{CONCLUSION}

It can be concluded that T3 group showed significant improvement in sublobular vein, interlobular vein, centralis vein, interlobular duct. In addition, the T3 group also represented significant improvement the scores of hepatocyte form, focal necrosis, hypertrophy, fibrosis, cholestasis, and steatosis.

\section{CONFLICTS OF INTEREST}

The authors would like to declare that there is no conflicts of interest with the data carried out in the manuscript.

\section{ACKNOWLEDGMENT}

The authors thank to Faculty of Veterinary Medicine, Universitas Airlangga for provide support this study through scheme Penelitian Dasar Disertasi (PDD) with grant No. 419/UN3.15/PT/2021.

\section{CONTRIBUTION DETAILS}

To be ticked marked (X) as applicable and add columns according to the number of authors.

\begin{tabular}{lcccc}
\hline Contribution & $\begin{array}{c}\text { M } \\
\text { Sukmanadi }\end{array}$ & MH Effendi & F Fikri & $\begin{array}{c}\text { MTE } \\
\text { Purnama }\end{array}$ \\
\hline Concepts or Ideas & $\mathrm{X}$ & $\mathrm{X}$ & $\mathrm{X}$ & $\mathrm{X}$ \\
Design & $\mathrm{X}$ & $\mathrm{X}$ & - & - \\
Definition of & $\mathrm{X}$ & $\mathrm{X}$ & $\mathrm{X}$ & $\mathrm{X}$ \\
intellectual content & $\mathrm{X}$ & $\mathrm{X}$ & $\mathrm{X}$ & $\mathrm{X}$ \\
Literature search & $\mathrm{X}$ & $\mathrm{X}$ & $\mathrm{X}$ & $\mathrm{X}$ \\
Experimental studies & $\mathrm{X}$ & $\mathrm{X}$ & $\mathrm{X}$ & $\mathrm{X}$ \\
$\begin{array}{l}\text { Data acquisition } \\
\text { Data analysis }\end{array}$ & $\mathrm{X}$ & $\mathrm{X}$ & $\mathrm{X}$ & $\mathrm{X}$ \\
$\begin{array}{l}\text { Manuscript } \\
\text { preparation }\end{array}$ & $\mathrm{X}$ & $\mathrm{X}$ & $\mathrm{X}$ & $\mathrm{X}$ \\
Manuscript editing & $\mathrm{X}$ & $\mathrm{X}$ & $\mathrm{X}$ & $\mathrm{X}$ \\
Manuscript review & $\mathrm{X}$ & $\mathrm{X}$ & $\mathrm{X}$ & $\mathrm{X}$
\end{tabular}

\section{REFERENCES}

1. McGill, M. R. (2016). The past and present of serum aminotransferases and the future of liver injury biomarkers. EXCLI journal, 15, 817.

2. Marchese, S., Polo, A., Ariano, A., Velotto, S., Costantini, S., \& Severino, L. (2018). Aflatoxin B1 and M1: Biological properties and their involvement in cancer development. Toxins, 10(6), 214.

3. Dai, Y., Huang, K., Zhang, B., Zhu, L., \& Xu, W. (2017). Aflatoxin B1induced epigenetic alterations: An overview. Food and Chemical Toxicology, 109, 683-689.

4. Nadi, M. S., Fikri, F., \& Purnama, M. T. E. (2020). Determination of Capsaicin Levels in Capsicum annum Linn Ethanolic Extract using Thin Layer Chromatography Analysis. Drugs, 70(14), 1831-1842. 
5. Ying, J., Xu, Q., Liu, B., Zhang, G., Chen, L., \& Pan, H. (2015). The expression of the PI3K/AKT/mTOR pathway in gastric cancer and its role in gastric cancer prognosis. OncoTargets and therapy, 8, 2427.

6. Gao, Y., Yang, J., Cai, Y., Fu, S., Zhang, N., Fu, X., \& Li, L. (2018). IFN- $\gamma-$ mediated inhibition of lung cancer correlates with PD-L1 expression and is regulated by PI3K-AKT signaling. International journal of cancer, 143(4), 931-943.

7. Deng, J., Bai, X., Feng, X., Ni, J., Beretov, J., Graham, P., \& Li, Y. (2019) Inhibition of $\mathrm{PI} 3 \mathrm{~K} / \mathrm{Akt} / \mathrm{mTOR}$ signaling pathway alleviates ovarian cancer chemoresistance through reversing epithelial-mesenchymal transition and decreasing cancer stem cell marker expression. BMC cancer, 19(1), 1-12

8. Fattori, V., Hohmann, M. S., Rossaneis, A. C., Pinho-Ribeiro, F A., \& Verri, W. A. (2016). Capsaicin: current understanding of its mechanisms and therapy of pain and other pre-clinical and clinical uses. Molecules, 21(7), 844

9. Purnama, M. T. E., Rahmaningtyas, I. H., Pratama, A. R., Prastika, Z., Kartikasari, A. M., \& Cahyo, N. P. D. (2019). Tadpole serum activity (Rana catesbeiana) in caspase-3 as a marker of the role of apoptosis and total cytotoxic T lymphocytes in albino mice' epithelial cells induced by neoplasia. Veterinary world, 12(1), 63.

10. Du, B., Zhang, Z., \& Li, N. (2014). Madecassoside prevents Aß25-35induced inflammatory responses and autophagy in neuronal cells through the class III PI3K/Beclin-1/Bcl-2 pathway. International immunopharmacology, 20(1), 221-228.

11. Liu, Y., Song, A., Wu, H., Sun, Y., \& Dai, M. (2021). Paeonol inhibits apoptosis of vascular smooth muscle cells via up-regulation of autophagy by activating class III PI3K/Beclin-1 signaling pathway. Life Sciences, 264, 118714.

12. Hamid, I. S., Aksono, E. B., Sukmanadi, M., \& Purnama, M. T. E (2018). Antiangiogenesis activity test of tin leaf (Ficus carica L.) on the number of blood vessels and VEGF expression of chorioallantoic membrane of embryonated chicken eggs. European Journal of Oncology Pharmacy, 1(4), e00007.

13. 13. Hamid, I. S., Ekowati, J., \& Purnama, M. T. E. (2019). Kaempferia galanga L. Inhibiting Effect on Vascular Endothelial Growth Factor (VEGF) and Cyclooxygenase-2 (Cox-2) Expression on Endothelium of Chorioallantoic Membrane. Indian Veterinary Journal, 96(9), 80-82.
14. Nasr, R., Hasanzadeh, H., Khaleghian, A., Moshtaghian, A., Emadi, A., \& Moshfegh, S. (2018). Induction of apoptosis and inhibition of invasion in gastric cancer cells by titanium dioxide nanoparticles. Oman medical journal, 33(2), 111.

15. Dufour, D. R., Lott, J. A., Nolte, F. S., Gretch, D. R., Koff, R. S., \& Seeff, L. B. (2000). Diagnosis and monitoring of hepatic injury. I. Performance characteristics of laboratory tests. Clinical chemistry, 46(12), 2027-2049.

16. Stracieri, L. D. D. S., \& Scarpelini, S. (2006). Hepatic injury. Acta Cirurgica Brasileira, 21, 85-88.

17. 17. Matsumoto, K., Umitsu, M., De Silva, D. M., Roy, A., \& Bottaro, D P. (2017). Hepatocyte growth factor/MET in cancer progression and biomarker discovery. Cancer science, 108(3), 296-307.

18. Pothula, S. P., Xu, Z., Goldstein, D., Biankin, A. V., Pirola, R. C., Wilson, J. S., \& Apte, M. V. (2016). Hepatocyte growth factor inhibition: a novel therapeutic approach in pancreatic cancer. British journal of cancer, 114(3), 269-280

19. Szkolnicka, D., Lucendo-Villarin, B., Moore, J. K., Simpson, K. J., Forbes, S. J., \& Hay, D. C. (2016). Reducing hepatocyte injury and necrosis in response to paracetamol using noncoding RNAs. Stem cells translational medicine, 5(6), 764-772.

20. 20. Porowski, D., Wirkowska, A., Hryniewiecka, E., Wyzgat, J. Pacholczyk, M., \& Paczek, L. (2015). Liver failure impairs the intrahepatic elimination of interleukin-6, tumor necrosis factor-alpha, hepatocyte growth factor, and transforming growth factor-beta. BioMed research international, 2015.

21. Al-Rasheed, N. M., El-Masry, T. A., Tousson, E., Hassan, H. M. \& Al-Ghadeer, A. (2018). Hepatic protective effect of grape seed proanthocyanidin extract against Gleevec-induced apoptosis, liver Injury and Ki67 alterations in mice. Brazilian Journal of Pharmaceutical Sciences, 54.

22. Choi, H. Y., Lee, J. H., Jegal, K. H., Cho, I. J., Kim, Y. W., \& Kim, S. C (2016). Oxyresveratrol abrogates oxidative stress by activating ERKNrf2 pathway in the liver. Chemico-biological interactions, 245, 110-121.

23. Thomas, D. L. (2019). Global elimination of chronic hepatitis. New England Journal of Medicine, 380(21), 2041-2050.

24. Chapa-Oliver, A. M., \& Mejía-Teniente, L. (2016). Capsaicin: from plants to a cancer- suppressing agent. Molecules, 21(8), 931 


\section{GRAPHICAL ABSTRACT}

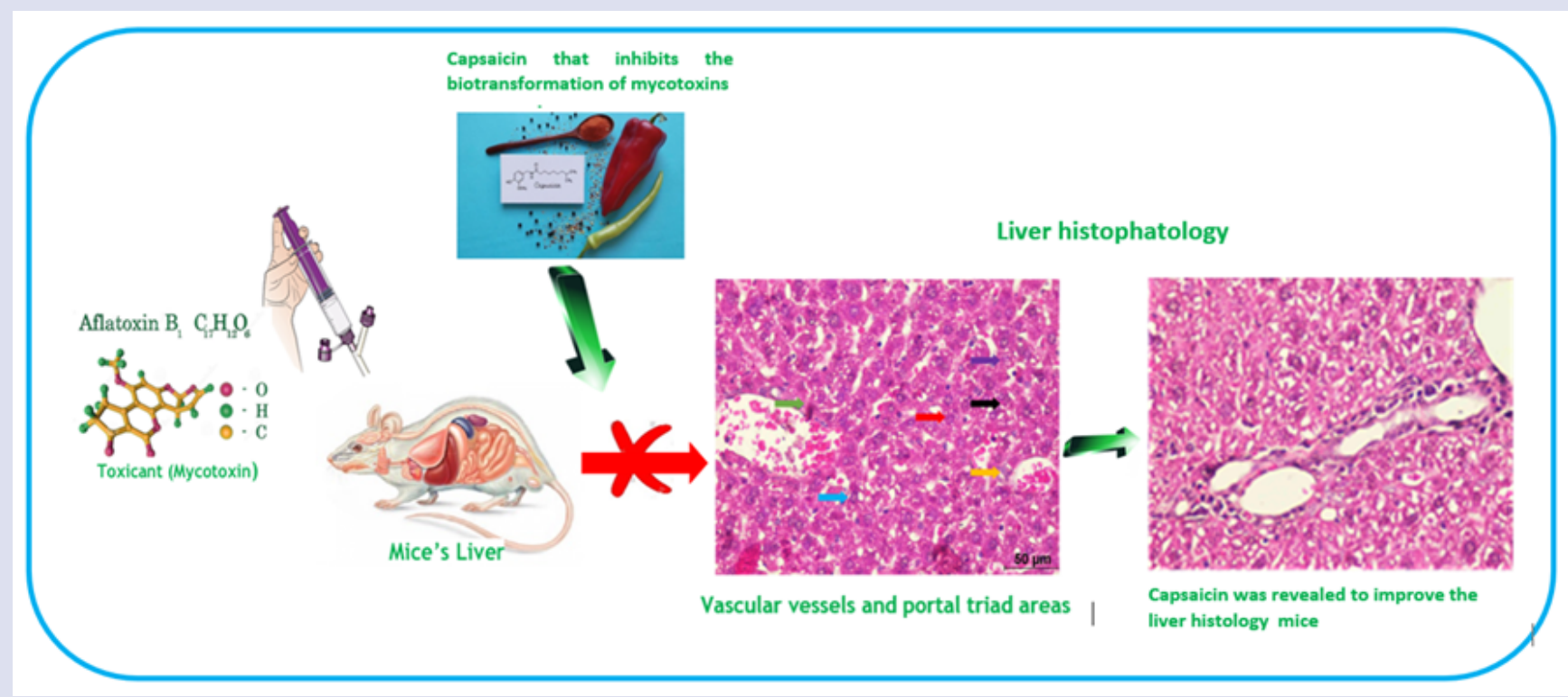

\section{ABOUT AUTHORS}

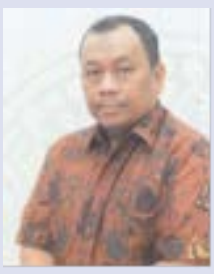

Dr. Mohammad Sukmanadi, DVM, MSc., Doctoral in Veterinary Science, Lecturer, Researchers; Veterinary Pharmacy Subdivision, Veterinary Basic Science Division, Faculty of Veterinary Medicine, Universitas Airlangga, Surabaya, Indonesia. His research focus is in the fields of Veterinary Pharmacy, Herbal Medicine, biomaterials and animal ethics. A total of 12 publications indexed by SCOPUS and 4 publications nationally accredited. He is registered as Member of Commission VI Division of Organizational Development and Training the Indonesian Veterinary Medical Association (IVMA).

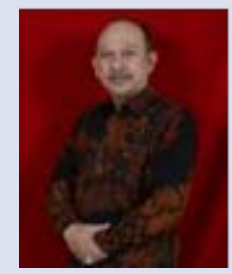

Prof. Dr. Mustofa Helmi Effendi, drh., DTAPH. was officially inaugurated as the 524th Professor of Universitas Airlangga (UNAIR) is Professor in Veterinary Epidemiology Head of $D$ i v i s i o $n$ of Veterinary Public Health, Faculty of Veterinary Medicine, $U$ n i v e r s i t a s Airlangga; His research focus is in the fields of Veterinary Epidemiology, AMR, , Biomaterials and Good Laboratory Practice (animal ethics). A total of $\mathrm{H}$-index 13, citations 379, 58 publications indexed by SCOPUS. He is registered as a member Idonesian Veterinary Medical Association (IVMA).

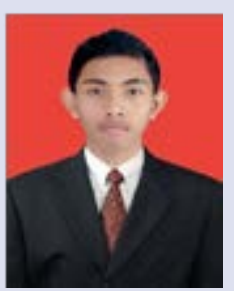

Muhammad Thohawi Elziyad Purnama, DVM., M.Sc. is a lecturer at the Department of Veterinary Anatomy, Faculty of Veterinary Medicine, Universitas Airlangga. His research focus is in the fields of anatomy, physiology, biomaterials and animal ethics. A total of 22 publications indexed by SCOPUS and 70 publications nationally accredited. He is registered as a member of the Federation Equestre Internationale (FEI) and the Indonesian Veterinary Medical Association (IVMA).

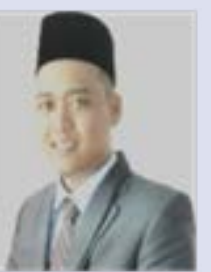

Faisal Fikri, DVM., M.vet. is a lecturer at the Department of Veterinary science, Faculty of Veterinary Medicine, Universitas Airlangga. His research focus is in the fields of phytochemistry, physiology, biomaterials and animal ethics. A total of 10 publications indexed by SCOPUS and 40 publications nationally accredited. He is registered as a member of the Indonesian Veterinary Medical Association (IVMA).

Cite this article: Sukmanadi M, Effendi MH, Fikri F, Purnama MTE. Liver-Histological Improvement after Capsaicin Administration in Mice with Aflatoxin B1 Toxication. Pharmacogn J. 2021;13(6)Suppl: 1577-1581. 